\title{
ESTUDIOS
}

\section{Las Tres Primeras Reseñas Londinenses de 1826 de La Victoria de Junin}

$\mathrm{D}^{\circ}$ ON José Joaquín de Olmedo, durante su tesidencia en la capital de Inglaterra como representante diplomático del Perú, dio en ella a la estampa una edición de su oda al Libertador: La Victoria de Junín Canto a Bolivar, por J. J. Olmedo, Reimpreso en Londres, 1826 (Londres: Publicado por R. Ackermann [Imprenta española de M. Calero], I826), 80 págs. y 3 grabados en acero. ${ }^{1}$ Era ésta, en efecto, la segunda edición del canto, tras la primera impresa en Guayaquil en mayo de r825. El papel y la tipografía son excelentes, según era habitual en las obras patrocinadas por Rodolfo Ackermann, editor londinense que por aquellos años publicaba numerosos libros, impresos en castellano, destinados al mercado de las recién independizadas repúblicas hispanoamericanas. ${ }^{2}$

1 Ver la descripción bibliográfica de la ed. de Londres en Poesías completas de José Joaquín de Olmedo, ed. Aurelio Espinosa Polit, S. I. (México, 1947), pp. 254-255 (que abrevio en lo sucesivo: Olmedo, Poesías completas). De dicha ed. londinense existe un ejemplar, de los de lujo $(\mathrm{de} 22 \mathrm{~cm}$.), en la Biblioteca de la Universidad de California, Berkeley, con dedicatoria autógrafa de Olmedo a su madre política doña Rosa Silva y Olave de Icaza; ejemplar obsequiado a la Biblioteca por nuestro amigo don Antonio Rodríguez-Moñino.

2 "Ver William Jeremiah Burke, "Rudolph Ackermann, Promoter of the Arts and Sciences, with a Selected List of His Publications in The New York Public Library," Bulletin of The New Yonk Public Library, Nueva York, XXXVIII, 10 y 11 (octubre y noviembre, 1934), 807-826 y 939-953, respectivamente. 
Como es sabido, el primer crítico del poema lo había sido el propio Bolívar, quien a la vista de la versión inicial, dirigió a Olmedo, desde el Cuzco, las dos famosas cartas de 27 de junio y de 12 de julio de 1825 respectivamente. ${ }^{3}$ Igualmente conocida es la reseña que de la edición de Londres hizo Andrés Bello en el número de octubre de 1826 de su Repertorio Americano. ${ }^{4}$ Menos conocida que ésta es, 'en cambio, aunque harto anterior en fecha, la primera de las reseñas de La Victoria de Junin a que dio lugar la edición londinense, e ignoradas hasta ahora, que yo sepa, son otras dos, también publicadàs en Londres en esa ocasión, y también anteriores a la de Bello. El más autorizado y reciente de los editores de las obras de Olmedo, el Padre Espinosa Polit, incluye la una en la nota bibliográfica relativa a estudios acerca de Olmedo que figura en su edición; pero desconoce las otras dos. ${ }^{5}$ Dar alguna noticia de las tres es el objeto de los presentes renglones.

La primera de las reseñas a que me refiero, "Examen de libros La Victoria de Junín, Canto a Bolívar, por J. J. Olmedo", aparece a las págs. $147-152$, del $^{\circ} 2$, de $1^{9}$ de abril de 1826 , del Correlo Literario y Politico de Londres, Periódico trimestre, por J. J. de Mora, redactado, según su título indica, por el emigrado liberal español, José Joaquín de Mora, y publicado, como reza la cubierta, por Rodolfo Ackermann, en Londres " $y$ en su Establecimiento de México, asimismo en Colombia, Buenos Aires, Chile, Perú y Guatemala". ${ }^{6}$ Nótese que el periódico lleva la fecha de $\mathrm{r}^{\circ}$ de abril siendo así que la edición de La Victoria de Junin

3 Verlas, p. ej., en Vicente Lecuna ed., Cartas del Libertador, V (Caracas, 1929), pp. 6-8 y 36-40, respectivamente.

4 A [ndrés] B[ello], "Noticia de La Victoria de Junín, Canto a Bolivar, por J. J. Olmedo, Reimpreso en Londres, 1826", El Repertorio Americano, Londres, I (octubre, 1826), pp. 54-61. Verla también en Andrés Bello, Obras completas, IX, Temas de critica literaria (Caracas, 1956), pp. 225-232. Del Repertorio hay ejemplar en la Biblioteca de la Universidad de California, Berkeley.

5 Olmedo, Poesias completas, pp. 306-309.

6 Del Correo aparecieron cuatro números los días $1^{\circ}$ de enero, abril, julio y octubre de 1826, respectivamente. De él he manejado la colección propiedad de la Biblioteca de la Universidad de la Carolina del Norte, Chapel Hill, cuyo préstamo agradezco. En todas las citas de éste y de otros textos del siglo XIX transcribo fielmente el contenido, pero modernizo la ortografía y la puntuación según las reglas y usos actuales. Sobre Mora (1783-1864) ver, p: ej., Miguel Luis Amunátegui, Don José Joaquin de Mora: Apuntes biográficos (Santiago de Chile, 1888), $351 \mathrm{pp}$. Sobre sus actividades en Londres, ver especialmente Vicente Lloréns Castillo, Liberales y románticos, Una emigración española en Inglaterra (1823-1834) (México, 1954), $382 \mathrm{pp}$, passim (Véase su índice). 
no fue dada a la luz sino a fines de dicho mes. ${ }^{7}$ Seguramente Mora la vio en pruebas en casa de Ackermann, editor tanto del poema como del periódico en el que se reseñaba.

Esta recensión del canto de victoria americano, además de su carácter de primicia, of rece la particularidad de ser debida a una pluma española.

El Sr. Olmedo - escribía Mora - se ha colocado a la altura del asunto. En general su estilo indica el estudio de los buenos originales y un conocimiento nada vulgar de la construcción rítmica. Su plan, diestramente disimulado en el desorden que caracteriza este género de composiciones, es ingenioso y sencillo. Una exposición llena de énfasis y majestad anuncia al lector los grandes hechos que van a ofrecerse a sus ojos. La escena corresponde al interés del drama que en ella va a representarse y está notablemente descrita.

Continúa luego el crítico explicando cómo el poeta presenta a Bolívar y le hace hablar a sus compañeros, cómo elogia a la juventud belicosa, cómo describe la victoria de Junín y la celebración del triunfo, con 1a aparición de Huaina Cápac y su profecía de Ayacucho:

plan [que] combina acertadamente la dificultad del doble asunto que se propone el autor y que sólo por un artificio ingenioso podía formar el stmplex et zinum, recomendado por Horacio, ${ }^{9}$ e indispensable en toda composición artística.

Uno de los grandes intereses de Mora, hábil versificador él mismo, es la técnica del verso, y juzga así la de Olmedo:

7 En carta fechada en Londres el 19 de abril de 1826 dice Olmedo a Bolivar: "El canto se está imprimiendo con gran lujo y se publicará la semana que entra". (Olmedo, Poesias completas, p. 254, o José Joaquín Olmedo, Epistolario, ed. Aurelio Espinosa Polit, S.I. [Puebla, México, 1960], pp. 263-265; la cita en la p. 263).

8 Hablando del héroe del poema dice Mora: "En América, una combinación feliz de circunstancias permite que se reúnan en el mismo individuo las más altas dignidades militares y civiles con el celo exclusivo por los intereses generales, y. que la fuerza y el prestigio de la opinión, puestos en manos de un hombre, sean instrumentos de ventura pública en vez de serlo de exaltación propia y de universal ruina". Un poco más tarde había de cambiar de opinión sobre Bolívar cuando éste propuso su constitución vitalicia. Ver, p. ej., su ar. tículo sobre ella en El Conciliador, Buenos Aires, No. 1 (y único publicado). Mayo, 1827 , pp. 25-43 (he consultado el ejemplar existente en la Biblioteca Nacional, Lima), y otros trabajos suyos, v.g., en la Crónica Politica y Literaria de Buenos Aires, $\mathrm{N}^{2} 43$, de 26 de julio de 1827 (que he visto en microfilm).

$9 \mathrm{La}$ alusión es al verso 23 del Arte Poética, de Horacio: "Denique sit "quod vis simplex dumtaxtat et unum". 
el autor posee la teoría de la versificación y sabe manejar su meca-nismo. El uso que hace de los versos cortos rimados con endecasílabos, que los preceden, da mucha gracia y variedad a su estilo. Este. además está revestido de un colorido que pudiéramos llamar local, por estar en armonía con los sitios que el poeta describe y cuyo. aspecto físico es tan diferente del paisaje europeo.

Acaba el redactor del Correo su reseña elogiando lo correcto y elegante de la impresión y la excelencia de los tres grabados que adornan: la obra, todo lo cual además de ser cierto constituía un gesto publicitario. en favor de Ackermann, su editor.

Una prueba más de la admiración de Mora por La Victoria de Junin y de su interés por anunciar esta edición la encontramos al ver que en: otra publicación suya, el No me olvides, de 1826 , págs. $342-346$, imprimió un fragmento del poema, el himno de las vírgenes del Sol, desde el verso "Alma eterna del mundo" hasta el que dice "Tuya es la tierra, y la victoria es tuya". 10

La resêña de la oda, según se ha visto, es muy favorable: elogia la: cultura literaria clásica, el estilo, el sentido rítmico y la buena versificación de Olmedo. El colorido local, que a un neoclásico puro hubiera: podido ser ofensivo, lo justifica Mora, quien en Londres había aprendido" a apreciarlo en la literatura inglesa, antigua y moderna, que tanto admiraba. El plan del poema, cuestión batallona sobre la cual los críticos están: aún hoy en desacuerdo, también lo aprueba el crítico andaluz sobre la: base de que está hábilmente disimulado en el "desorden que caracteriza: este género de composiciones", cita indirecta de Boileau que Olmedo: (quizás siguiendo a Mora) utiliza igualmente en su carta a Bolívar, fe-.-

10 "Himno de las Vírgenes del Sol, después de la batalla de Junín", corr la nota: "Sacado del poema intitulado La Victoria de Junín, Canto a Bolivar, por Don J. J. Olmedo, cuya segunda edición acaba de publicar el Sr. Ackermann con tres hermosas estampas", No me olvides: Colección de producciones en prosa y verso, originales y traducidas por José Joaquín de Mora (Londres: R. Ackermann, 1826), pp. 342-346. Los No me olvides fueron unos volúmenes anuales. que Áckermann editó en Londres, de 1824 a 1829. Los de 1824 a 1827 son obras de Mora, los dos restantes de Pablo Mendíbil. La Biblioteca Bancroft de la Universidad de California, Berkeley, posee ejemplares de los de 1824, 1825, $1826 \mathrm{~g}$ 1828; del de 1827 he manejado el ejemplar existente en la Biblioteca del Wagner Free Institute of Science, de Filadelfia, Pennsylvania (Del de 1829 existe ejemplar en la Biblioteca de Salvá, en Valencia, España; ver Llórens, Liberales y ro. mánticos, p. $192 n$ 30). El No me olvides de 1826 salió entrado el año: el: Correo Literario y Político de Londres, $\mathrm{N}^{\circ} 3$, de $1^{\circ}$ de julio de 1826, p. 222, anuncia que dicho No me olvides "ha sufrido un retraso inevitable" y ofrece que el de 1827 se publicará puntualmente a principios del año siguiente. 


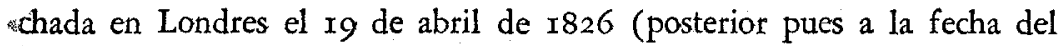
No 2 del Correo): "El bello desorden es el alma de la oda, como dice su mismo Boileau de usted". 11 A Mora le parecía un "artificio ingenioso" - el de la aparición del Inca como medio para unificar el tema de Junín con el de Ayacucho, artificio que había agradado poco al Libertador. ${ }^{12}$ En fin, la total aprobación de Mora al plan del canto le parece al Padre Espinosa Polit una defensa de amigo. ${ }^{13}$ Mora, en efecto, lo fue de Olmedo.

Debieron conocerse precisamente en Londres, en casa de Ackermann, y prueba de sus relaciones amistosas es la epístola en verso que Mora dirigió a Olmedo en su No me olvides, de $x 827$, pp. $272-275,{ }^{14}$ con el título "A D. J. J. Olmedo, autor de La Victoria de Junín, Canto a Bohlivar", que empieza:

No es sólo el numen destructor, Olmedo, de la sangrienta lid, quien de tu patria

los lauros triunfadores apercibe $\ldots{ }^{15}$

El elogio de Mora al Canto a Bolivar debió seguir siendo de la buena memoria y el agrado de Olmedo, y del gusto de sus admiradores contemporáneos, por cuanto en la última edición suelta de él, hecha en vida del poeta y es de suponer que con su anuencia, el viejo artículo de aquél figura como prólogo: La Victoria de Junin, Canto a Bolivar por I. Joaquin de Olmedo, Nueva edición revisada con esmero, ordenada bajo inuevo plan y aumentada con el examen critico de la obra publicado por Don José Joaquin de Mora en el "Correo Literario y Politico de Londres", año de 1826 (Caracas: Impreso por George Corser, I842).16

11 Olmedo, Epistolario, p. 264. Boileau, en efecto, decía en los versos 63-64, Canto II, de su Arte Poética, refiriéndose a la oda: "Son style impétueux souvent marche au hasard;/Chez elle un beau désordre est un effet de l'art".

12 Carta de Bolívar a Olmedo, de 12 de julio de 1825, cit. $n 3$ supra.

13 Olmedo, Poesias completas, p. LV. Debe señalarse que en la p. 306 del -mismo libro el P. Espinosa Polit dice que esta reseña de Mora fue "reproducida en :El Mercurio Chileno, $\mathrm{N}^{\circ} 12$, pp. 545 ss." Lo que en dicho $\mathrm{N}^{\circ}$ y pp. 545-550 aparece no es esto sino otro artículo de Mora relativo a otra obra de Olmedo. 'Ver $n 16$ infra.

14 No me olvides: Colección de producciones en prosa y verso, originales y traducidas por José Joaquín de Mora (Londres: R. Ackermann, 1827), XI378-6 pp. y 13 grabados. Agradezco al Wagner Free Institute of Science, de Filadelfia, el préstamo de su ejemplar de este No me olvides. Ver $n 9$ supra.

15 Un comienzo de respuesta a esta epístola de Mora pudiera ser el fragmento, de seis versos a él dirigidos, hallado en un manuscrito de Olmedo. Verlo en sus Poesias completas, p. 217.

16 Ver su descripción bibliográfica en Olmedo, Poesías completas, pp. 255. 
La segunda de las reseñas que nos ocupan apareció con el título* "La Victoria de Junín, Canto a Bolívar, por J. J. Olmedo, Reimpreso: en Londres en 1826, en la imprenta española de M. Calero, 8vo. de80 pp. con tres láminas finas", en Ocios de Españole's Emigrados, Londres, No 28 , de julio de I826, pp. $78-84 .{ }^{17}$ No lleva firma; pero su: autor debió ser ya don Joaquín Lorenzo Villanueva o bien Pablo Mendíbil, los dos principales redactores de la revista en materia de bellas. letras. ${ }^{18}$

En contradistinción con Mora y el Correo, el reseñante de La Victoria de Junin en los Ocios hace un par de veces la salvedad de que quiere evitar "ingratos recuerdos que hieren el amor nacional" y puntos. que resulten "desapacibles" a alguna de las partes interesadas en los hechos referidos en el poema; pero igualmente declara que tampoco quiere "defraudar a las musas de su derecho justísimamente adquirido. por medio de tan bella composición, [ni] a la poesía castellana de un homenaje debido por una de las composiciones que más la honran"; porque él encuentra en el poema de Olmedo:

bellezas, frecuentemente derramadas en las breves páginas que lo. componen, [que] son capaces de borrar por el momento de la lectura, la triste impresión que en todo buen español han debido dejar los sucesos que han separado para siempre del regazo de la madre

256. Es posible que Mora y Olmedo hubieran vuelto a verse al pasar éste por Valparaíso en agosto de 1828 , de regreso de su misión diplomática en Londres y París, y en momentos de gran valimiento de Mora en Chile. En la revista que allí publicó Mora (de la que hay copia microfilmada en Berkeley), aparece un artículo titulado "Poesía, Ensayo sobre el hombre de Mr. Pope, Versión de D. J. J. Olmedo, Lima, 1823", El Mercurio Cbileno, Santiago de Chile, N' 12, $1^{\circ}$ de marzo de 1829 , pp. 545-550. Comenta el Ensayo sobre el bombre de $M$. Pope, Versión del inglés por J. J. Olmedo (Lima: Imprenta de José Masías, 1823), 45 pp., que incluía sólo su traducción de la primera epístola del Essay on Man. Como es sabido, Olmedo tradujo dos epístolas más de este poema. Mora, a vuelta de encontrar algunos lunares en la traducción, hace de ella y de Olmedo grandes elogios; elogios que éste debió siempre recordar con gusto por cuanto en una carta fechada en Guayaquil el 10 de enero de 1840 y enviada. a Andrés Bello, en Santiago de Chile, le pedía que le buscase y le remitiese un ejemplar de ese número del Mercurio (Ver Olmedo, Epistolario, p. 292).

17 Ocios de Emigrados Españoles fue un periódico publicado en Londres pos algunos expatriados liberales de 1823. Alcanzó 35 números, 31 mensuales, de abril de 1824 a octubre de 1826 , y ottos cuatro trimestrales, en una $2^{2}$ serie publicada de enero a octubre de 1827 , con un total general de 3,228 pp. La Biblioteca Bancroft de la Universidad de California, Berkeley, posee una colección de sus siete tomos.

18 Sobre Ocios y sus redactores ver Lloréns, Liberales y románticos, pp. 255274, principalmente. 
común a unos pueblos, hermanos del nuestro, a quienes no podemos menos de desear tanta ventura como a nosotros mismos.

Con esas precauciones ante posibles susceptibilidades patrióticas, la reseña de $O$ cios es tan favorable y entusiasta como la del Correol; y no debe dejar de anotarse, frente a los sueños reconquistadores de Fernando VII, de los absolutistas y corifeos de la Santa Alianza, el reconocimiento por parte del redactor español de los Ocios de la separación "para siempre" de las repúblicas hispanoamericanas, y sus votos por la ventura de aquellos pueblos hermanos.

Halla el comentarista de Ocios que la combinación del relato de las dos acciones de Junin y Ayacucho está tan bien realizado que el brillo de la una no perjudica al de la otra ni al buen orden en la disposición del poema:

antes bien de esta misma circunstancia ha sabido sacar el Sr. Olmedo todas las ventajas que la abundancia de ideas y la mayor extensión del cuadro podían proporcionarle para of recer los pensamientos más escogidos, las imágenes más vivas, los lances más dignos de celebrarse, las hazañas más brillantes y los consejos más propios para guiar a los que quizás tendrán todavía necesidad de aconsejarse con el valor y la prudencia, si han de acabar de consolidar la obra de la libertad.

El plan de la composición le parece, pues, "uno de los primores que más resaltan en él [el poema] por lo sencillo, al mismo tiempo que por lo completo y copioso en inspiraciones muy adecuadas al géneto lírico".

Agrada en particular al reseñante la introducción, "presentada con notable pompa poética", y de la que cita un trozo; y continúa ejemplificando el vigor poético de Olmedo con fragmentos del poema que muestran lo arduo de la pelea y la belicosidad de los patriotas. Prosigue su reseña explicando así la importancia de la aparición del Inca:

La máquina poética de introducir la aparición del Inca Huaina Cápac, que predice a los guerreros de Junín la nueva lid que les espera en Ayacucho y sus resultados, forma el nudo de las dos partes que componen el poema. La profecía del antiguo monarca del Perú es en cierta manera apoyada con la nueva maravilla de un himno cantado por las vírgenes del Sol, con el cual se retraza la alegría, la majestad 
y el entusiasmo del carmen saeculare que cantaba la juventud ro. mana.

No creo que pueda hacerse comparación más laudatoria para este famoso pasaje, del que cita desde el verso "Alma eterna del mundo" hasta el que dice "Y arredre a sediciosos y tiranos". Según se vio antes también le parecía a Mora este himno uno de los mejores trozos del poema.

Comenta finalmente el reseñante de los Ocios la dulzura y la gracia de los versos que pintan el acompañamiento del carro de la Victoria $y$ 'de aquellos en los que el poeta habla a su musa. Termina el artículo con estas palabras:

Por estas muestras se ve que La Victoria de Junín revela en el Sr. Olmedo un poeta capaz de ejercitarse en los grandes argumentos con que los destinos del vasto continente americano y los favores que la naturaleza ha derramado en él no dejarán de brindarle, imponiéndole al mismo tiempo con sus inspiraciones, tan privilegiadas como las de este canto, la obligación de contribuir al lustre de la poesía hispanoamericanà.

En esta reseña de los Ocios de Emigrados Españoles, a vuelta de algunas precauciones verbales - ante posibles susceptibilidades, exacerbadas en exilados por la nostalgia patriótica y en ciudadanos de países recién independizados por el sobreexcitado nacionalismo-, se evidencia claramente el sentimiento de solidaridad con que aquellos liberales, derrotados en la Península, observaban el triunfo de la libertad en América. Como un ejemplo más de ello puede mencionarse que en el $\mathrm{N} \% \mathrm{r} 6$, de julio de 1825, pp. 24-27, de los Ocios, se había impreso ya un poema titulado "Al Padre de Colombia y Libertador del Perú, Canción nacional", anónimo allí pero de la pluma del vate colombiano José Fernández de Madrid, que empezaba así:

Tres siglos eternos el nuevo hemisferio

En vil servidumbre sumido gimió;

Temblad ¡oh tiranos! finó vuestro imperio,

América es libre, vuestra hora sonó . . .19

19 De las Poesías de Fernández de Madrid no tengo a la mano más que la edición de La Habana, 1830, en la que (como es de esperar en una obra publi- 
La reseña nos muestra, en fin, cómo apreciaban, en términos generalmente derivados de la preceptiva clasicista, un poema tal como La Victoria de Junín de tanta inspiración y empaque clásicos.

La última de las ignoradas reseñas a que me refería es la aparecida en The New Montbly Magazine and Literary Journal, 1826, Part III, Historical Register, Londres, $2^{9}$ serie, vol. XVIII, $x^{9}$ de setiembre de 1826 , pp. 363-364. Figura en su sección de "Critical Notices", subsección de "Foreign Publications", bajo el epígrafe "La Victoria de Junín, Canto a Bolívar por J. J. Olmedo, I2mo. Reimpreso en Londres I826 (The Victory of Junin, an Ode to Bolivar, By J. J. Olmedo)".20 Era entonces director del New Montbly Magazine Thomas Campbell, el poeta de "Battle of the Baltic" $y$ de "Ye Mariners of England", amigo de libe. rales españoles desterrados y de patriotas hispanoamericanos. La reseña, como la mayoría de las reseñas en revistas inglesas de aquella época, no lleva indicación de quién sea su autor. Había de ser alguien versado en el idioma castellano y conocedor de la literatura española: Los pasajes que del canto traduce al inglés indican, con una sola excepción, un exacto entendimiento del original; las referencias a la literatura peninsular son oportunas; pero por otra parte parece desconocer la existencia de toda literatura poética americana anterior a esa oda y creer también que Bolívar estuvo presente tanto en Ayacucho como en Junín.

Comienza la reseña explicando que el poema es una novedad como obra que es del Enviado Extraordinario de la República del Perú en Londres, y que: "We look with interest to the literary labours, however trifling, of nations which, having just burst the chains of slavery and ignorance, have sprung forward in the race of civilization and the arts." En este caso, la Musa, siempre fiel a la causa de la libertad, habla desde

cada en la Cuba española de los últimos años del reinado de Fernando VII) no figuran composiciones de carácter político o patriótico ameticano. El poema en cuestión figuró en la ed. de las Poesías, de Londres, 1828, con bastantes variantes al parecer respecto al texto de los Ocios de 1825 . La ed. de 1828 no me ha sido accesible; pero ver la larga cita de este poema en la reseña que de esa ed. apareció en la revista de Mora, El Mercurio Cbileno, Santiago de Chile, No. 16,15 de julio de 1829 , pp. 749-756, reseña que Pedro Grases atribuye a don Andrés Bello y considera su primera contribución escrita en Chile (Ver Obras completas de Andrés Bello, IX, p. 289).

20 Del New Montbly Magazine he manejado la colección existente en la Biblioteca de la Universidad de California, Berkeley. Mora mencionó esta reseña en la sección "Variedades", de su Correo Literario y Político de Londres, $\mathrm{N}^{\circ} 4$, de $1^{\circ}$ de octubre de 1826, p. 372 . 
un nuevo Parnaso, desde un país nuevo en los anales de la literatura, país que está invirtiendo el orden natural de las cosas puesto que, en vež de dinero, envía versos a Inglaterra, mientras que Inglaterra envía dinero a las tierras de la plata y del oro, en vez de enviarles los productos de las Musas.

El reseñante explica a sus lectores ingleses que el poema está escrito a la manera de las canciones italianas, en el tipo de estrofa larga que los líricos españoles imitaron de Petrarca y de Chiabrera. Encuentra en Olmedo, inflamado de virtud patriótica, no pequeño talento poético; y prosigue:

The author's great classical acquirements are visible in the present composition, which, for elevation of thought, colouring of imagination, and harmony of meter, is worthy of the best literature of Old Spain, equal to the "Battle of Lepanto," by the divine Herrera, or, of its living poets, to that of Quintana to the battle of Trafalgar.

En prueba de ello cita en castellano veinticuatro versos del comienzo del poema y los traduce en prosa inglesa, traduciendo igualmente otros ocho de la descripción de Bolívar, dieciocho del parlamento de Huaina Cápac y ocho de los que Olmedo dirige a su musa al final de la composición. Parece probable que estos fragmentos sean la primera versión al inglés, aunque parcial, de La Victoria de Junin; por ello los copio en un apéndice a estas líneas.

El crítico del New Montbly Magazine observa que poema tal, procedente del Nuevo Mundo, demuestra cuán rápidamente el vigor de la inteligencia se despliega bajo las ramas del árbol de la libertad; y termina deseando a Olmedo que por mucho tiempo pueda seguir componiendo dulces versos bajo los naranjos y los tamarindos de su país recién liberado: Tiempos mejores - tiempos de paz y libertad-esperan a América. A las nubes que oscurecen su horizonte seguirá, sin duda, un largo verano. Sus naciones serán dentro de poco poderosas, libres y prósperas; y Olmedo vivirá indudablemente para verlo y para cantar las glorias de su país en la paz como lo ha hecho en la guerra; su patriótica musa obtendrá con ello su mejor galardón.

En una forma muy apropiada para los lectores a que va dirigida, esta reseña se ocupa principalmente en describirles el contenido del poema y en presentarles varios ejemplos de su texto, algunos en castellano y en su traducción inglesa, otros solamente en esta versión. No deja, sin. 
embargo, de ofrecerles también alguna nota de crítica literaria: Indicación del origen de la forma adoptada por el poeta; de la educación clásica de éste que se tefleja en su obra; del valor de su pensamiento, de su imaginación y de su técnica, con una oportuna referencia a otras dos obras castellanas posiblemente conocidas de los lectores ingleses interesados en literatura española, literatura que la guerra de la independencia contra la invasión napoleónica y las subsiguientes luchas del liberalismo en la Península habían puesto de moda entre una considerable parte del público británico culto a partir de 1808 . La guerra de la independencia hispanoamericana, como la de los griegos, había atraído igualmente tanto la participación de combatientes británicos como la general simpatía del público inglés. Una obra de la envergadura de La Victoria de Jumín, reseñada, venía a justificar en el campo del progreso cultural aquellas simpatías.

Resumamos. La reseña del Correo Literario y Politico de Londres, la de los Ocios de Emigrados Españoles, la del New Montbly Magazine, y la subsiguiente del Repertorio Americano, coinciden en elogiar la corección y riqueza del lenguaje y del estilo de Olmedo en La Victoria de Junín, su vigor y su dulzura, su construcción métrica, la altura de su pensamiento, la variedad del contenido del poema, y la cultura clásica del autor y los reflejos que de ella se perciben en la obra. En la cuestión de la aparición del Inca como medio de unificar el tema de Junín con el de Ayacucho, Mora, el crítico de los Ocios, y Bello, coinciden también en aprobatla como un artificio ingenioso, como uno de los primores del poema, como un medio ingenioso, respectivamente. Tanto Mora como Bello se basan específicamente para esto en la libertad concedida por los preceptistas al poeta lírico en la costrucción de la oda. El reseñante de los Ocios y el del Repertorio Americano discrepan al considerar aquél que Olmedo ha sacado de dicha máquina poética todas las ventajas que ofrece el haber dado una mayor extensión al cuadro, mientras que a éste, por el contrario, le parecía la obra demasiado larga para un rapto de entusiasmo lírico. Todos hallan que Olmedo ha sido digno de su grande argumento.

En lo literario, lo esencial de las reseñas estál fundamentado en los criterios del neoclasicismo, ligeramente atemperados por un feliz aprecio del color local, pródromo del romanticismo. En lo político, todos los 
reseñantes, los españoles, el inglés y el venezolano, están hermanados. en la gran fraternidad de sentimiento y pensamiento liberal.

Luis Monguió

\author{
University of California \\ Berkeley.
}

\begin{abstract}
APENDICE
The New Monthly Magazine and Literary Journal, 1826, Part III, Historical Register, Londres, $2^{\mathrm{a}}$ serie, vol. XVIII, $\mathrm{I}^{\mathrm{9}}$ de setiembre de 1826 .

[p. 364a] "Those proud pyramids, which the temerity of human art has elevated to heaven, to discourse with future ages, and to all nations-temples, the work of slaves to deify their tyrants, -these are the sport of Time, who but brushes them with his decrepit wing, and they are levelled with the earth. The passing wind obliterates their lying inscriptions, and they disappear among their ruins, in the darkness of everlasting oblivion. Models of impotence and ambition! The priests, the temple, and the god, are alike annihilated!

"But the sublime mountains that rear their summits into the ethereal realms-that behold tempests flash, howl, break, and disperse at their feet-the Andes,- - those vast, stupendous piles, founded upon beds of gold, and balancing the world with their weight-they will never move!--they scorn the power of Time and the fury of Envy-they will be eternal heralds of Liberty and Victory."
\end{abstract}

[p. $364 \mathrm{~b}$ ] "They say-O marvel unheard of!-that the beautiful name of Columbia, graven upon his helmet, sheds around rays of glory so refilgent, that the dazzled Spaniard trembles, faints, loses voice and motion, or preserves them but for flight. Thus 
some guilty wretch, at midnight, raising his weapon, lets it fall again faint and trembling, if Heaven suddenly dart its lightning-a mortal cold succeeds his fury-and he recedes, shuddering and fear-struck!"

[p. 364b] "War to the usurper! What owe we to him? Knowledge; manners, religion, or laws, when we were ignorant, wicked, ferocious, superstitious? What religion-that of Jesus? Blasphemers ; they brought us blood, the swift bullet, chains; these were their sacraments! The false prophet of Medina did not establish his creed with more destruction.* O Religion! pure and sacred fount of love and consolation to man, what evils have been perpetrated in thy name! What ties of love did they bring us? In return for hospitality and the most generous offices, they gave us fetters--for gratitude, torments. This did they all, save one, the martyr of his love of America-thou, divine Las Casas! - the apostle of peace and charity, worthy of another nation!"

[p. 364b] "I shall return to my loved flute, wandering free through the shady grove of oranges and thick tamarinds, or by the painted and fragrant rose that adorns the margin of my river, or in smiling fields, where with proud lofty throne and exalted crown, the apple-tree boasts the Scepter of Pomona."

* Esta frase traduce dos versos que Olmedo mandó suprimir al imprimirse el poema, por última vez en vida suya, en la América poética (Valparaíso, 1846). 
